\title{
Uma nota "conservadora" sobre o comércio internacional
}

\author{
Antonio Carlos Macedo e Silva*
}

RESUMO - O artigo sugere que, esvaziada a bolha das commodities verificada entre 2002 e 2008, a estrutura do comércio internacional voltará a apresentar as tendências pregressas (perda de participação dos produtos primários e ganho por parte dos produtos intensivos em tecnologia), reiterando o caráter problemático da inserção comercial de países como o Brasil.

Palavras- chave: Intensidade tecnológica do comércio internacional. Comércio exterior brasileiro.

Estamos em 1950 e fazemos uma pergunta a especialistas: o que vai acontecer com o comércio internacional nas próximas décadas? Os especialistas disfarçam, mas no fundo não sabem. O comércio internacional é o ponto fraco de Bretton Woods: a carta de Havana virou letra morta, a Organização Internacional do Comércio foi abortada pela resistência do Congresso norte-americano. Os economistas de formação neoclássica expressarão o desejo de que, em prol da eficiência produtiva e da harmonia entre as nações, as enormes barreiras ao comércio sejam progressivamente derrubadas, abrindo espaço à especialização dos países segundo suas vantagens comparativas. Os países mais ricos, relativamente mais ricos em capital, exportarão produtos manufaturados; os países mais pobres, mais ricos em trabalho ou recursos naturais, exportarão bens intensivos nesses fatores.

Mas queremos algo além de wishful thinking e insistimos: alguma outra opinião? Talvez não seja muito inverossímil supor que um dos economistas do grupo já tenha lido o primeiro Estudo Econômico publicado um ano antes pela Comissão Econômica da América Latina, da ONU. ${ }^{8}$ Nesse caso, quem sabe se disponha a mencionar duas teses lá defendidas: a demanda por produtos industriais crescerá mais rapidamente do que a demanda por primários; ocorrerá, em parte por essa razão, uma deterioração dos termos de troca dos países especializados nesses últimos produtos. (Talvez, por uma questão de prudência, o atento leitor de relatórios oficiais se abstenha de mencionar as implicações normativas dessas idéias pouco usuais.)

Estamos em 2000. Os especialistas têm à sua disposição 50 anos de história e uma quantidade de dados - para não falar da capacidade de processá-los - muitas e muitas vezes

\footnotetext{
* Doutor em Economia pela Universidade Estadual de Campinas. É Professor Assistente do Instituto de Economia e pesquisador do Centro de Estudos de Conjuntura e Política Econômica (CECON) da UNICAMP. Endereço Eletrônico: macedo@eco.unicamp.br.

${ }^{7}$ Agradeço a colaboração dos bolsistas do CNPq-PIBIC, Eduardo Alvarenga de Melo e Pedro Henrique Thubes Forquesato, as sugestões de Esther Dweck e a Gabriel Porcile a imagem de Ricardo vingador.

${ }^{8}$ Refiro-me, obviamente, a Prebisch (1948).
} 
maior. O que vai acontecer nas próximas décadas? A resposta talvez comece por uma constatação trivial e fácil de explicar: o comércio internacional continuará a crescer mais rapidamente do que o PIB global. ${ }^{9}$ Não há, afinal, indícios de que o processo de liberalização comercial empreendido pelo GATT e pela OMC - principal responsável por esse resultado venha a ser revertido. Tudo indica, além disso, que a participação dos produtos primários nas exportações globais siga em queda. ${ }^{10} \mathrm{E}$ que o espaço perdido continue a ser ocupado pelos produtos industriais mais complexos ou sofisticados. (A explicação? Bem, por que não começar pela do velho Prebisch?)

Estando em 2000, demasiadamente ocupados com o debate sobre a "nova economia" e as tendências da Nasdaq, os especialistas não têm olhos para ver o que se avizinha. Não prevêem (os mais otimistas) a recessão global de 2001, e muito menos o estranho ciclo expansivo que se iniciará a seguir, no qual os países em desenvolvimento contribuirão em proporções inusitadas para o crescimento do PIB e do comércio internacional. Tampouco prevêem que ocorrerá, entre 2002 e 2008, a maior alta dos preços das commodities dos últimos 50 anos, engolfando (em ordem de intensidade decrescente) petróleo, metais e alimentos.

De 2002 em diante, os especialistas terão a oportunidade de prever mais coisas inusitadas, como o decoupling dos países emergentes e, em particular, uma nova era de ouro para os exportadores de commodities - ou não é verdade que o rápido crescimento econômico e a intensa demanda de primários por parte das economias asiáticas são mudanças estruturais no perfil da demanda global? David Ricardo está de volta, e (como se diz em inglês) with a vengeance...

Mas o fato é que estamos, aqui e agora, perto do fim de 2008, em meio ao maior desastre financeiro desde a grande depressão. E o que observamos, ao contemplar o gráfico 1 deste texto, são as assustadoras quedas nos preços das commodities ocorridas no curto período entre julho e novembro do ano corrente: 42\%para o índice geral Reuters/Jefferies-CRB e de $59 \%$ no preço do petróleo. Não há indícios de que o movimento tenha encontrado seu piso.

\footnotetext{
${ }^{9}$ Entre 1992 e 2000, o PIB global cresceu a uma taxa média anual de 3,2\%; para o volume do comércio de bens e serviços, a taxa foi de 7,4\%. No ciclo mais recente, de 2001 a 2007, as taxas anuais foram, respectivamente, de 4,3\% e 6,2\%. Os dados provêm da base do World Economic Outlook, atualizada em outubro de 2008, http://www.imf.org/external/pubs/ft/weo/2008/02/weodata/index.aspx.

10 Tomemos, por exemplo, o período entre 1980 e 2007. O comércio global da última categoria expandiu-se (em dólares correntes) a uma taxa anual de $8,3 \%$, muito à frente dos produtos agrícolas $(5,0 \%)$ e da agregação de combustíveis e minerais (5,9\%). Dados da base estatística da WTO, acessada em novembro de 2008, http://www.wto.org/english/res_e/statis_e/statis_e.htm .
} 
Nessas circunstâncias, o que deve dizer um economista interessado nas tendências do comércio internacional? Se for mesmo inevitável dizer alguma coisa - pois talvez fosse preferível abster-se de qualquer comentário! - o economista pode escudar-se nas últimas previsões do FMI. No mais recente update do World Economic Outlook, ${ }^{11}$ a instituição prevê, para o próximo ano, recessão global, ${ }^{12}$ com um crescimento do produto de $2,2 \%$ e de apenas $2,1 \%$ do comércio. Uma indicação de quão pantanosa é a base para qualquer previsão está no fato de que, no update, publicado um mês após o relatório, o FMI reduziu a cifra relativa ao comércio em nada menos do que 2 pontos percentuais.

GRÁFICO 1 - ÍNDICES DE PREÇOS DE COMMODITIES (1967=100) - 1/1970 -11/2008

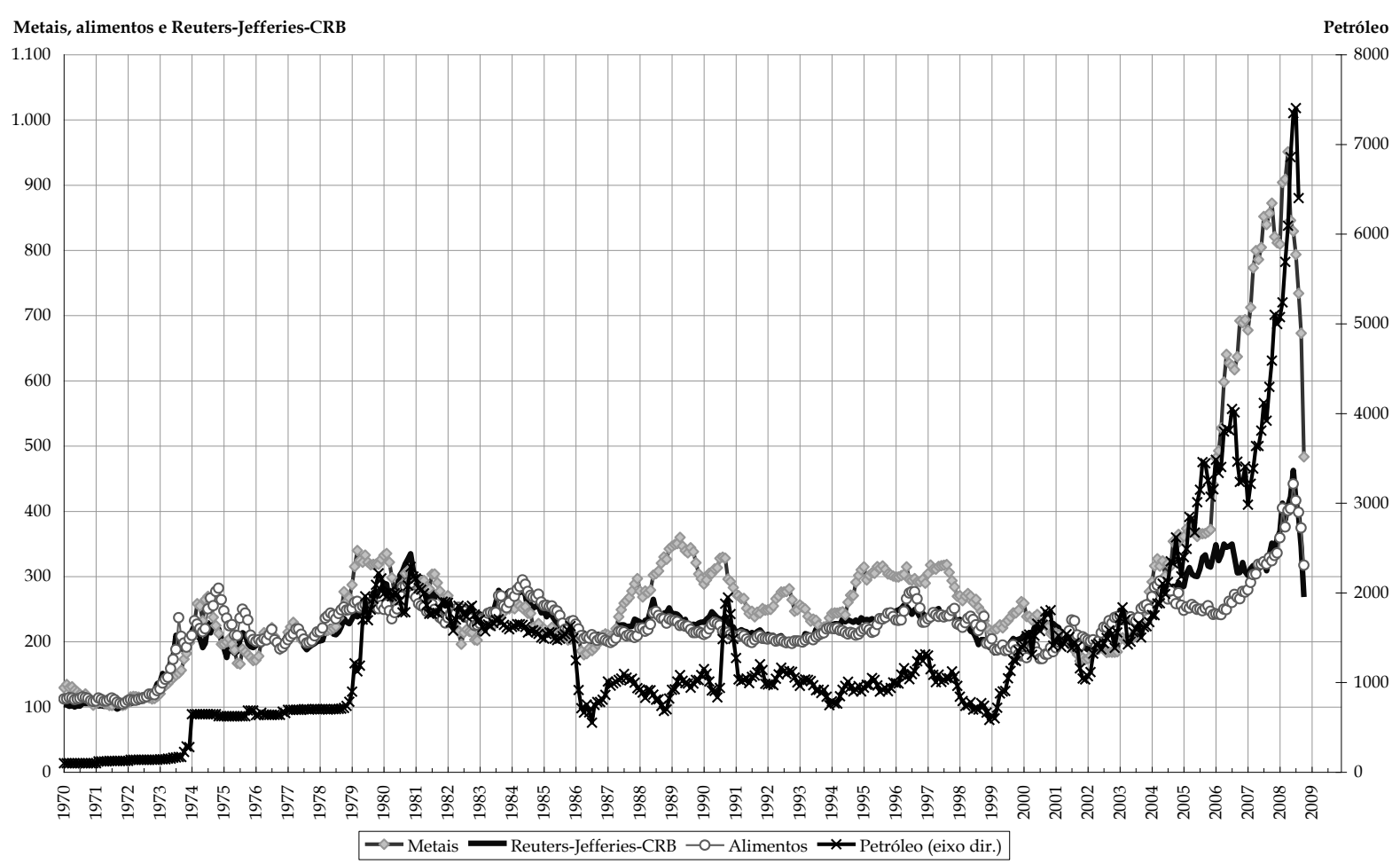

FONTE: FMI no caso do petróleo (os valores para os meses de outubro e novembro foram estimados com base em dados da Energy Information Administration, EIA) e CRB para as demais séries (http://www.crbtrader. com/crbindex/). Elaboração própria.

Mas... e depois disso? A queda abissal dos preços das commodities lança uma sombra sobre a tese da era de ouro das commodities, fortalecendo a posição dos que atribuíram parte considerável da alta anterior a operações de natureza especulativa (ver, por exemplo, Unctad, 2008). Diante disso, este economista prefere apostar - de forma conservadora - na

11 Divulgado no dia 6 de novembro de 2008, em http://www.imf.org/external/pubs/ft/weo/2008 /update/03/index.htm.

12 Adotando aqui regra prática segundo a qual, para a economia mundial, um crescimento anual inferior a 3\% caracteriza "recessão". De fato, em anos de "recessão" global, a relação entre taxas de crescimento do PIB e do comércio internacional pode se inverter. Assim foi, por exemplo, em 2001, quando a expansão do comércio não chegou a $0,3 \%$, contra um crescimento do PIB de $2,2 \%$. 
continuidade de algumas das tendências verificadas nas últimas décadas. E é à luz dessa hipótese que convida o leitor - após uma brevíssima discussão sobre comércio e crescimento no próximo item - a examinar, na parte final, alguns dados relativos à estrutura das exportações e importações de alguns países (inclusive o Brasil) e blocos de países. Contrariando a boa praxe acadêmica, o texto abstém-se de uma conclusão formal e termina com uma indagação.

Alterações na composição da demanda global não são mera curiosidade empírica. São significativas mesmo no âmbito da mais austera abordagem ricardiana. Afinal, podem afetar os termos de troca entre os países e, com isso, a distribuição entre eles dos "ganhos do comércio". Porém, na tradição teórica neoclássica, que se apropriou com fervor da teoria das vantagens comparativas, o comércio internacional não tem conexões claras com $\mathrm{O}$ crescimento econômico - que foi em geral analisado no contexto da economia fechada.

Mas em economia não há somente um "cânone”. Como lembra Reinert (1994), uma tradição longeva e alternativa defende a tese de que a criação de riqueza é "setor-específica". Vale dizer, a natureza do que a economia produz (e exporta) tem implicações significativas sobre o crescimento econômico. ${ }^{13}$

Curiosamente, essa tradição, que remonta aos mercantilistas, pode listar o próprio Adam Smith entre seus tributários. Para Smith, nenhuma atividade é tão propícia ao progresso da divisão do trabalho - e portanto ao aumento da produtividade - quanto a indústria. De forma mais obscura, Smith sugeriu igualmente que os mercados externos poderiam representar, para um país, uma fonte adicional de demanda. ${ }^{14}$

Esse segundo ponto, porém, só ganharia um sentido claro com a contribuição de Keynes em sua Teoria Geral. Trata-se simplesmente de extrair um corolário da idéia de que a produção de riqueza nas economias capitalistas é em geral constrangida pela demanda: se isso é assim, o crescimento econômico de um país será favorecido por sua especialização na produção de bens cuja demanda global seja particularmente dinâmica - capaz, portanto, de tornar-se uma fonte de demanda líquida e de divisas. ${ }^{15}$

\footnotetext{
${ }^{13}$ Este item resume idéias expostas em Macedo e Silva (2008), onde o leitor poderá encontrar maiores detalhes, além de referências bibliográficas aqui omitidas.

${ }^{14}$ No que foi, aliás, criticado por Say e Ricardo.

$15 \mathrm{~A}$ referência às divisas remete à assimetria entre devedores e credores, tratada (muito rapidamente) por Keynes no final do segundo volume de seu Tratado sobre a Moeda.
} 
A questão setorial, obviamente, nunca esteve (como tampouco o tema do desenvolvimento) entre as prioridades de Keynes. A articulação entre as intuições de Smith (retomadas por List e, depois, por Young) e o princípio da demanda efetiva seria obra de economistas como Prebisch, Singer e Kaldor. A ênfase de Singer e Prebisch na conexão entre industrialização e desenvolvimento encontra um eco na tese kaldoriana de que a relação entre crescimento da produção e crescimento da produtividade é particularmente intensa na indústria. As preocupações de Prebisch com as vicissitudes de uma inserção internacional baseada na exportação de produtos primários (e sua defesa de políticas que fomentem a aquisição de competitividade na exportação de manufaturados) ganham na teoria do crescimento com restrição de divisas - elaborada por discípulos de Kaldor, como Thirlwall uma expressão mais rigorosa.

Um outro fio da meada se estende de Kaldor a economistas neo-schumpeterianos. Uma boa síntese é a de Dosi, Pavitt \& Soete (1990): há setores que são simultaneamente "eficientes" de um ponto de vista keynesiano (uma vez que geram exportações, amenizando a restrição externa ao crescimento) e do ponto de vista schumpeteriano (dado que contribuem diretamente e por meio de vários tipos de externalidades ao progresso técnico e ao aumento da produtividade). Setores que produzem bens intensivos em tecnologia tendem a ser altamente eficientes nesses dois sentidos do termo.

Para toda essa literatura - bem como para a abordagem muito mais recente e muito menos heterodoxa de Hausmann e Rodrik ${ }^{16}$ - não é mera coincidência o fato de que os países em desenvolvimento de maior crescimento nas últimas décadas sejam também aqueles em cujas estruturas produtivas a indústria ganhou maior ponderação e cujas pautas de exportação mais intensa e rapidamente se concentraram em produtos mais "nobres". ${ }^{17}$

\section{II}

Milhares de tipos distintos de bens são transacionados internacionalmente. Sem adotar algum tipo de procedimento classificatório, a massa de informação é impenetrável. A definição da estratégia, porém, não é nada trivial: há mais de duas dezenas de taxonomias setoriais (Kaplinsky e Santos Paulino, 2003).

16 O argumento schumpeteriano é de certa forma retomado por Hausmann e Rodrik (ver por exemplo Hausmann e Rodrik, 2003 e 2006, Haussmann et al, 2005, Rodrik, 2006). O eventual sucesso dos pioneiros devidamente estimulados por políticas governamentais (inclusive a cambial e a "industrial") apropriadas - em uma nova atividade acaba atraindo imitadores, deslocando recursos produtivos para atividades de produtividade mais alta e acelerando o crescimento do produto.

${ }^{17}$ Hausmann e Rodrik, assim como Lall et al. (2005), trabalham com o conceito de "sofisticação" dos bens, caso em que sua "nobreza" é inferida da participação relativa que apresentam na pauta exportadora dos países desenvolvidos. 
Adoto aqui a classificação elaborada pela Unctad, que distribui os bens conforme "o mix de diferentes intensidades em capacitação técnica [skills], tecnologia e capital e diferentes características de escala" (Unctad, 2002: 87). ${ }^{18}$ Toda taxonomia tem seus defeitos. Alguns dos defeitos desta estão em seu caráter estático (pois os setores são classificados de uma vez por todas), demasiadamente agregado e parcial (setores que são high-tech em países desenvolvidos podem não merecer o mesmo rótulo em um país em desenvolvimento; ver, a respeito, Furtado e Carvalho, 2005). ${ }^{19}$ Entre as virtudes, o uso relativamente difundido, a existência de séries longas (pelo menos desde 1985) e a simplicidade. ${ }^{20}$

A tabela 1 (cujo título toma a parte pelo todo, referindo-se apenas à intensidade tecnológica) descreve a evolução da composição do valor nominal das exportações globais entre 1985 e $2006 .^{21}$ A comparação entre as duas pontas sugere que o movimento concentra-se em duas categorias: ${ }^{22}$ a participação dos primários caiu em 5,8 pontos percentuais; os produtos high-tech tiveram, por seu turno, um ganho de 6,3 pontos. Na comparação entre 2000 e 2006, o tão propalado boom das commodities primárias - que afetou tanto preços quanto volumes aparece como um modesto ganho de meio ponto percentual. Variação significativa ocorre, isto sim, na participação dos "energéticos", expressando as tradicionais oscilações dos preços do petróleo. Os dados de 2007 mostrarão certamente um aumento maior da participação dos primários (considerando o acelerado crescimento de preços de metais e alimentos no ano). $\mathrm{O}$ desabamento corrente dos preços das commodities e as razões prebischianas de sempre - que, aliás, transcendem a polêmica hipótese de uma tendência à deterioração nos preços relativos das commodities - sugerem que os produtos high-tech logo voltarão a liderar o crescimento das transações comerciais.

\footnotetext{
18 A Unctad, porém, desconsidera o comércio internacional de combustíveis (carvão, petróleo, gás natural). Os pesquisadores do Neit-Unicamp (ver Neit, 2007) agruparam alguns dos itens desprezados numa nova categoria, aqui denominada "energia".

19 Além disso, a fragmentação das cadeias de produção permite a exportação de bens que, embora classificados como high-tech, são de fato produzidos em condições - como a famosa maquila mexicana - em que é baixíssima a adição de valor e as externalidades acima referidas estão ausentes. Ver, a respeito, Akyüz (2005). Uma crítica mais ampla a esse tipo de classificação pode ser encontrada em Lall et alii (2005).

${ }^{20}$ Estratégias taxonômicas semelhantes foram adotadas pela Unido (ver Lall, 2000) e pela OCDE.

21 Os dados provêm do Comtrade, das Nações Unidas, que apresenta, para cada país, os números em dólares correntes do comércio exterior. Foi aqui utilizada a revisão 2 da SITC (Standard International Trade Classification). O Comtrade divulga apenas dados anuais, com um atraso de aproximadamente um ano; os dados relativos a 2007 ainda não estão disponíveis.

22 À guisa de ilustração, em 2006, alguns dos itens de maior peso no comércio global foram: nos primários, cobre, alumínio e carne; nos produtos "energéticos", óleo cru, derivados de petróleo e gás natural; nos intensivos em trabalho e recursos naturais, móveis, papel e papelão, têxteis e calçados; nos produtos low-tech, artigos de ferro e aço e navios; nos medium-tech, automóveis de passeio, motores para automóveis e maquinaria elétrica; nos hightech, equipamento de telecomunicações, chips e produtos farmacêuticos.
} 
TABELA 1 - INTENSIDADE TECNOLÓGICA DAS EXPORTAÇÕES GLOBAIS

\begin{tabular}{l|c|c|c|c|c|c}
\hline \multicolumn{1}{c|}{ Descrição } & $\mathbf{1 9 8 5}$ & $\mathbf{1 9 9 0}$ & $\mathbf{1 9 9 5}$ & $\mathbf{2 0 0 0}$ & $\mathbf{2 0 0 5}$ & $\mathbf{2 0 0 6}$ \\
\hline Primários & 17,8 & 15,9 & 14,9 & 11,5 & 11,6 & 12,0 \\
Energia & 13,2 & 8,4 & 5,8 & 10,1 & 12,5 & 13,9 \\
Intensivos em trabalho e recursos naturais & 12,0 & 14,4 & 14,6 & 13,0 & 11,5 & 10,7 \\
Baixa intensidade tecnológica & 7,7 & 7,0 & 6,9 & 5,8 & 6,8 & 6,9 \\
Média intensidade tecnológica & 24,2 & 26,3 & 25,9 & 24,9 & 24,4 & 23,6 \\
Alta intensidade tecnológica & 21,0 & 23,1 & 26,5 & 29,2 & 27,9 & 27,3 \\
Não classificados & 4,1 & 4,8 & 5,5 & 5,5 & 5,4 & 5,7 \\
\hline
\end{tabular}

FONTE: Comtrade. Elaboração Cecon.

É importante perceber que a progressiva concentração do comércio internacional nos produtos high-tech caracteriza as exportações tanto dos países desenvolvidos quando dos países em desenvolvimento, como mostra o gráfico $2 .{ }^{23}$ Entre 1990 e 2005, em contraste com a relativa estabilidade na estrutura das exportações dos países desenvolvidos, ocorreram mudanças formidáveis para o agregado dos países em desenvolvimento, com a migração para os setores de média e alta tecnologia.

GRÁFICO 2 - INTENSIDADE TECNOLÓGICA DAS EXPORTAÇÕES DE PAÍSES DESENVOLVIDOS (ESQUERDA) E PAÍSES EM DESENVOLVIMENTO (DIREITA) EM 1990 E $2005(\%)$
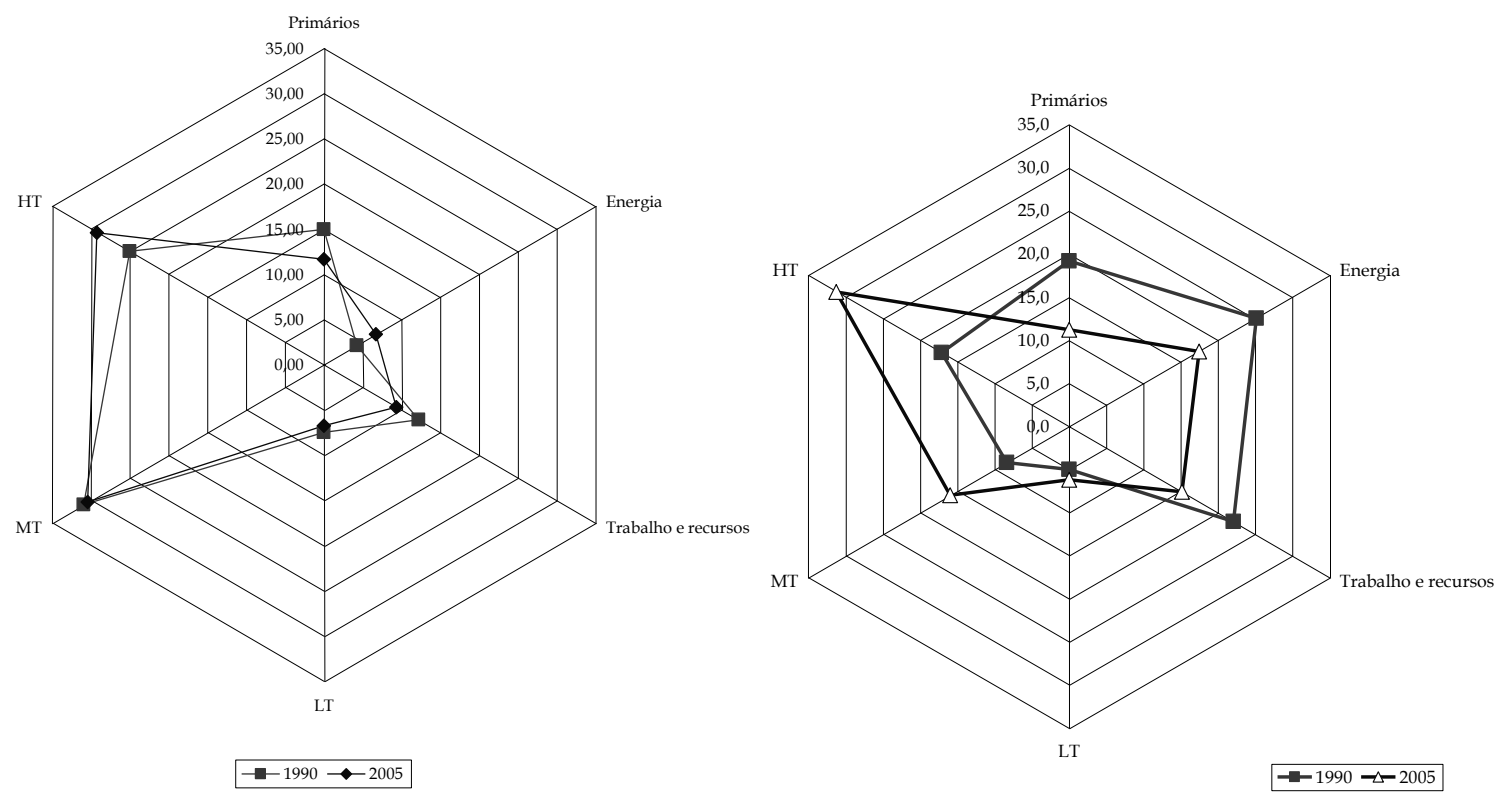

FONTE: COMTRADE. Elaboração CECON.

Essa transformação estrutural, entretanto, concentrou-se fortemente nos países asiáticos. Uma maneira sintética de perceber a diferença consiste em comparar as mudanças nas exportações da Coréia do Sul e do Brasil, entre 1985 e 2006 (gráfico 3). A disparidade

${ }^{23}$ Seguindo o procedimento sugerido por Lall (2000), tendo em conta problemas com os dados nacionais, foram excluídos do agregado dos países em desenvolvimento os países em transição do leste europeu e da Ásia Central. 
entre Coréia e Brasil é semelhante àquela existente entre China, Malásia e Tailândia, de um lado, e Argentina, Chile e Venezuela, de outro. ${ }^{24}$

Um último conjunto de dados oferece mais uma forma de perceber a falta de sintonia (um outro decoupling...) entre as tendências do comércio global e a evolução da pauta exportadora brasileira. Com os números fornecidos pela Organização Mundial do Comércio, é fácil identificar os importadores mais dinâmicos - e, por conseguinte, os mercados mais promissores. Apenas dez países foram responsáveis, entre 2001 e 2007, por 51\% da expansão das importações globais. Os dois primeiros, Estados Unidos e China, responderam, respectivamente, por 10,8\% e 9,2\% dessa expansão. ${ }^{25}$ Considerando que os 10 importadores mais dinâmicos estão também entre os principais exportadores, não surpreende o fato de que também a estrutura tecnológica das importações desse grupo de países tenha se movido na direção de produtos bigh-tech. De fato, a participação dos primários caiu, para o conjunto, entre 1985 e 2006, de 18,6\% para 12,6\%; a dos produtos bigh-tech aumentou de 17,9\% para $27,6 \%$.

A tabela 2 mostra, nas duas primeiras seções, a estrutura tecnológica das importações globais norte-americanas e chinesas. Ambas exibem as mesmas tendências, apenas mais dramáticas no caso da China, dados a abertura comercial e o acelerado crescimento a partir dos anos 90. Mesmo no caso do mais notório devorador de commodities do globo, a participação dos primários - à exceção, é claro, dos produtos "energéticos", onde a China tornou-se importadora líquida - caiu de forma significativa entre 1985 e 2006; no período mais recente, o aumento foi bem inferior àquele dos produtos high-tech.

\footnotetext{
${ }^{24} \mathrm{Na}$ América em desenvolvimento, a exceção é o México (cujas exportações bigh-tech passaram de 10,3\% a 25,8\% da pauta entre 1990 e 2006), mas sob as condições referidas em nota anterior. Para Argentina, Chile e Venezuela, as variações, foram, para o mesmo período e respectivamente, de $7,5 \%$ a $9,3 \%$, de $2,5 \%$ a $4,7 \%$ e de 2,0\% a 1,2\%. Nos casos de China, Malásia e Tailândia, as variações foram de $13,3 \%$ a $37,2 \%$, de 31,7\% a 50,2\% e de $18,6 \%$ a $33,4 \%$.

${ }^{25}$ Os demais países são (em ordem decrescente) Alemanha, França, Holanda. Reino Unido, Japão, Itália, Bélgica e Espanha.
} 
GRÁFICO 3 - INTENSIDADE TECNOLÓGICA DAS EXPORTAÇÕES DE CORÉIA DO SUL (ESQ.) E BRASIL (DIR), 1985 E 2006 (\%)
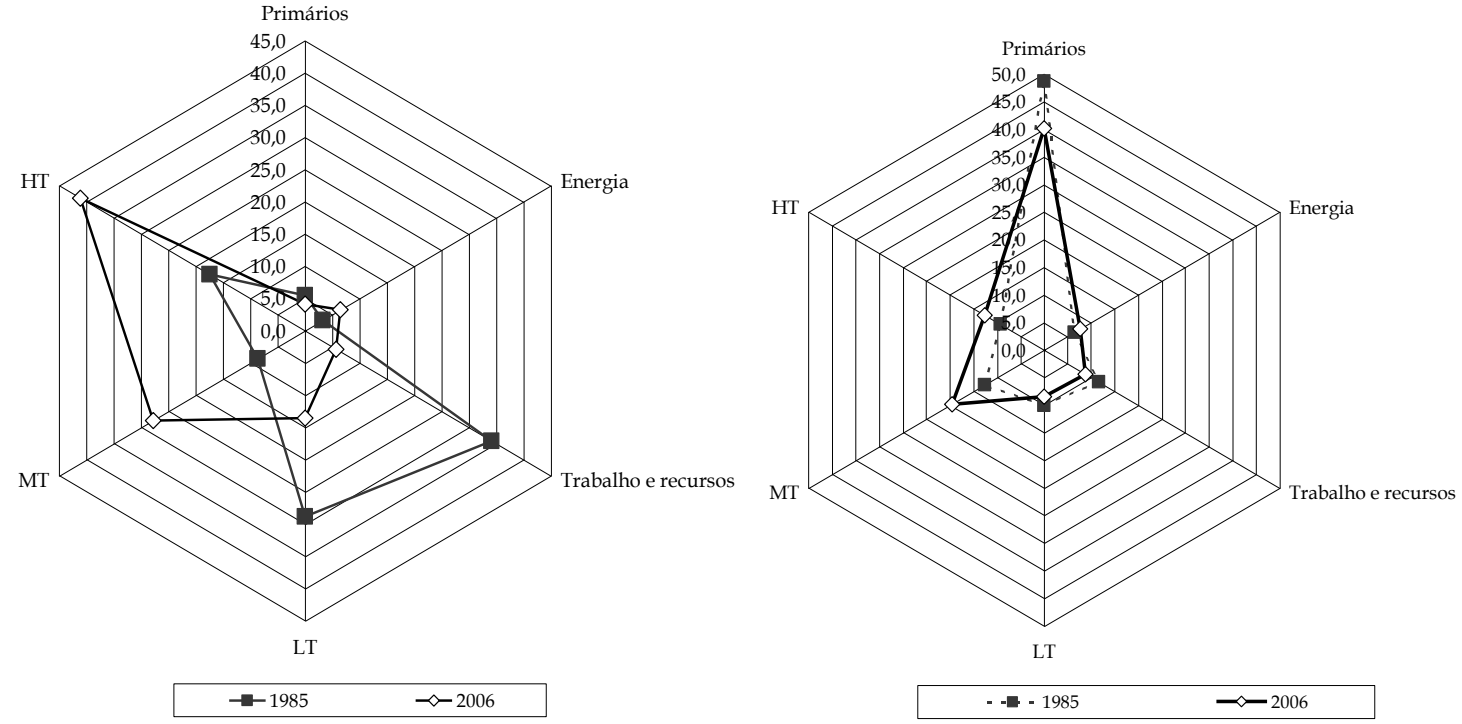

FONTE: COMTRADE. Elaboração CECON.

A última seção do gráfico mostra que o Brasil exporta, para os 10 mercados mais dinâmicos, uma cesta de bens cada vez mais concentrada em primários e "energéticos". 26 Ressalte-se que, no caso de nossa pauta exportadora para a China, o viés é ainda mais acentuado: em 2006, a categoria de primários respondeu por $81,0 \%$ de nossas vendas ao país; do valor total destas, apenas $2,2 \%$ couberam a produtos high-tech. ${ }^{27}$

Que conclusões tirar? De um ponto de vista ortodoxo, com ou sem era de ouro, o melhor que o Brasil tem a fazer (e vem fazendo) é abraçar suas vantagens comparativas estáticas. Já a leitura desenvolvimentista de dados como esses rapidamente descritos sugere que o decoupling entre a estrutura do comércio internacional e a das exportações brasileiras é motivo de inquietação e um tópico que não pode estar ausente da agenda política nacional.

\footnotetext{
26 A participação excepcional dos produtos high-tech, em 2000, deveu-se ao forte aumento das vendas externas de aviões e equipamentos, partes e acessórios de telecomunicações.

27 Produtos primários e high-tech geraram, em 2006, 19,4\% e 14,9\% das importações norte-americanas do Brasil.
} 
TABELA 2 - INTENSIDADE TECNOLÓGICA DAS IMPORTAÇÕES GLOBAIS NORTEAMERICANAS E CHINESAS E DAS EXPORTAÇÕES BRASILEIRAS PARA OS 10 IMPORTADORES MAIS DINÂMICOS (\%)

\begin{tabular}{|c|c|c|c|c|c|c|}
\hline \multicolumn{7}{|c|}{ Importações norte-americanas } \\
\hline Descrição & 1985 & 1990 & 1995 & 2000 & 2005 & 2006 \\
\hline Primários & 12,1 & 10,8 & 9,6 & 7,7 & 7,7 & 8,2 \\
\hline Energia & 15,4 & 13,3 & 8,2 & 11,1 & 17,2 & 18,0 \\
\hline Intensivos em trabalho e recursos naturais & 14,8 & 16,2 & 16,2 & 15,8 & 15,1 & 14,3 \\
\hline Baixa intensidade tecnológica & 5,8 & 4,6 & 4,8 & 4,5 & 4,9 & 5,1 \\
\hline Média intensidade tecnológica & 28,5 & 28,8 & 28,2 & 26,9 & 24,9 & 24,6 \\
\hline Alta intensidade tecnológica & 17,7 & 20,5 & 27,2 & 27,5 & 24,5 & 24,1 \\
\hline Não classificados & 5,7 & 5,8 & 5,8 & 6,5 & 5,8 & 5,7 \\
\hline \multicolumn{7}{|c|}{ Importações chinesas } \\
\hline Descrição & 1985 & 1990 & 1995 & 2000 & 2005 & 2006 \\
\hline Primários & 29,8 & 17,4 & 16,5 & 14,4 & 15,3 & 15,3 \\
\hline Energia & 0,4 & 2,4 & 3,9 & 9,2 & 9,8 & 11,3 \\
\hline Intensivos em trabalho e recursos naturais & 1,4 & 16,0 & 14,8 & 11,0 & 5,0 & 4,5 \\
\hline Baixa intensidade tecnológica & 22,7 & 8,0 & 7,3 & 5,7 & 5,2 & 4,0 \\
\hline Média intensidade tecnológica & 17,4 & 29,9 & 27,8 & 20,6 & 19,3 & 19,3 \\
\hline Alta intensidade tecnológica & 22,0 & 24,9 & 28,1 & 37,2 & 44,3 & 44,4 \\
\hline Não classificados & 6,3 & 1,5 & 1,7 & 1,8 & 1,3 & 1,2 \\
\hline \multicolumn{7}{|c|}{ Importações do Brasil por parte dos 10 importadores mais dinâmicos } \\
\hline Descrição & 1985 & 1990 & 1995 & 2000 & 2005 & 2006 \\
\hline Primários & 54,0 & 51,1 & 55,6 & 46,9 & 49,9 & 51,6 \\
\hline Energia & 5,3 & 3,1 & 0,7 & 2,9 & 6,1 & 7,1 \\
\hline Intensivos em trabalho e recursos naturais & 13,1 & 13,7 & 14,5 & 12,4 & 11,4 & 10,3 \\
\hline Baixa intensidade tecnológica & 7,0 & 9,5 & 8,4 & 7,4 & 8,3 & 7,6 \\
\hline Média intensidade tecnológica & 10,8 & 13,2 & 12,4 & 12,0 & 12,7 & 12,4 \\
\hline Alta intensidade tecnológica & 8,6 & 8,3 & 6,3 & 13,6 & 9,3 & 9,0 \\
\hline Não Classificados & 1,3 & 1,2 & 2,1 & 4,8 & 2,3 & 2,1 \\
\hline
\end{tabular}

FONTE: Comtrade. Elaboração Cecon.

\section{REFERÊNCIAS}

AKYÜZ, Y. Impasses do desenvolvimento. Novos Estudos, São Paulo, n. 72, p. 41-56, jul. 2005.

FURTADO, A. T.; CARVALHO, R. de Q. Padrões de intensidade tecnológica da indústria brasileira: um estudo comparativo com os países centrais. São Paulo em Perspectiva, São Paulo, v. 19, n. 1, p. 70-84, jan./mar. 2005.

HAUSMANN, R.; RODRIK, D. Economic development as self-discovery. Journal of Development Economics, v. 72, p. 603-633.

HAUSMANN, R.; RODRIK, D. Doomed to choose: industrial policy as a predicament (rascunho). Disponível em: <http://ksghome.harvard.edu/ drodrik/doomed.pdf $>$. Acesso em 18/12/2008. 
HAUSMANN, R.; HWANG, J; RODRIK, D. What you export matters. NBER Working Paper, Cambridge, Massachusetts, n. 11905, Dec. 2005. Discussão.

KAPLINSKY, R.; PAULINO, A.S. Innovation and competitiveness: trends in unit prices in global trade. Oxford Development Studies, v. 33, n. 3 \& 4, p. 333-355, Sep. 2005.

LALL, S. The technological structure and performance of developing country manufactured exports, 1985-1998. Oxford Development Studies, v. 28, n. 3, p. 337-369, Oct. 2000.

ZHANG, J.; WEISS, J.; LALL, S. The 'sophistication' of exports: a new measure of product characteristics. ADB Institute Discussion Paper, Tokyo, n. 23, Jan. 2005. Discussão.

MACEDO E SILVA, A. C. Estrutura produtiva e especialização comercial: algumas observações. Cadernos do Desenvolvimento. (no prelo).

NEIT. Evolução do comércio exterior brasileiro no período 2002-2006. Boletim NEIT, Campinas, n. 8, abril 2007. Disponível em: < http://www.eco.unicamp.br/Downloads/ publicacoes/neit/boletim_neit_08.pdf $>$. Acesso em 18/12/2008.

PREBISCH, R. O desenvolvimento econômico da América Latina e alguns de seus problemas principais. In: BIELSCHOWSKY (Org.). Cinqüenta anos de pensamento na CEPAL. São Paulo: CEPAL/COFECON/Record, 1949.

REINERT, E.S. Catching-up from way behind. A third world perspective on first world history. In: FAGEBERG, J.; VERSPAGEN, B.; VON TUNZELMAN, N. The dynamics of technology, trade and growth. London: Edward Elgar, 1994.

RODRIK, D. What's so special about China's exports? China \& World Economy, v. 14, n. 5, p. 1-19, Oct. 2006.

UNCTAD. Trade and development report. Vários números. 
